\title{
Biochemical Characterization of the Human Carbonic Anhydrase Variant CA Ih Hiroshima
}

\author{
R. J. Tanis*, W. R. A. Osborne**, N. Ueda****, and R. E. Tashian* \\ Department of Human Genetics, University of Michigan School of Medicine, Ann Arbor, \\ Michigan, USA, and Biochemical Genetics Section, Department of Clinical Laboratories, \\ Radiation Effects Research Foundation, Hijiyama, Hiroshima, Japan
}

Received February 20, 1976 / March 30, 1976

Summary. Some biochemical properties of a new red cell human carbonic anhydrase variant, CA Ih Hiroshima, have been determined. Evidence is presented that the amino acid substitution in the Japanese variant is not the same as the previously characterized CA Ic variant from Guam of similar electrophoretic mobility. Based on a comparison with the normal CA I isoenzyme, a proposal for the site of the amino acid substitution is presented.

There currently exist in the literature several examples of independently ascertained electrophoretic variants of serum and erythrocyte proteins which demonstrate apparently identical mobility during starch gel electrophoresis. Such variants, observed across a number of human populations, are of special interest to human geneticists. From the standpoint of understanding population dynamics, it is important to determine whether such "electrophoretically identical" variants represent the same amino acid alteration in the protein, in which case a common origin with dispersion by migration is the probable explanation, or whether a variety of different substitutions have resulted in variants with the same electrophoretic mobility. The latter situation would suggest multiple independent origins through mutation.

Recently we have observed an electrophoretic variant of human red cell carbonic anhydrase I (CA I), designated CA Ih Hiroshima, which appeared to have an electrophoretic mobility nearly identical to the previously reported CA I variant, CA Ic (Tashian et al., 1963; Lie-Injo, 1967; Lie-Injo and Poey-Oey, 1970; Lie-Injo et al., 1971). These reports document the occurrence of the CA Ic variant at low frequencies in both mongoloid (Java, Malaysia and U.S. Filipinos) and Oceania (Mariana Islands) populations. It was therefore of importance to determine if the CA Th Hiroshima variant represented a distribution of the CA Ic allele into the Japanese population or alternatively, if it represented a new genetic variant of CA I. We have undertaken to chemically characterize the Japanese

\footnotetext{
* Department of Human Genetics, University of Michigan School of Medicine, Ann Arbor, Michigan, 48109.

** Present address: Department of Pediatrics, University of Washington, Seattle, Washington.

*** Present address: Department of Clinical Laboratories, Kochi Prefectural Central Hospital, Kochi, Japan.
} 
variant and to compare our results to those previously reported for the CA Ic Guam variant (Tashian et al., 1966).

This communication describes an initial chemical characterization of the Japanese carbonic anhydrase variant using the techniques of peptide mapping, heat denaturation, and azosulfonamide difference spectra.

\section{Materials and Methods}

The Japanese CA I variant was initially detected during a survey of individuals who are part of the Radiation Effects Research Foundation Adult Health Study in Hiroshima and Nagasaki, Japan. From one of the individuals, presenting the variant pattern, an additional $40 \mathrm{ml}$ of whole blood was drawn and used for these biochemical characterization studies. From this sample approximately $5 \mathrm{mg}$ of purified variant protein was obtained using the techniques described below.

Neoprontosil, 7-acetamido-2,-(4'-sulphamyl phenylazo)-1-hydroxynaphthalene-3, 6-disulphonate, was obtained from Winthrop Laboratories, New York. All other chemicals were reagent grade and supplied by the Sigma Chemical Company.

Purification of the variant enzyme was carried out using the affinity chromatography method of Osborne and Tashian (1975). This was followed by ion exchange chromatography using a CM-32 column. The latter column was required to separate the purified CA Ih from normal CA I. The concentration of the purified enzymes was determined by measuring the extinction at $280 \mathrm{~nm}$ and employing a molar absorbance value of $4.8 \times 10^{4}$ liter mole ${ }^{-1} \mathrm{~cm}^{-1}$.

Standard two dimensional fingerprint techniques (Tashian et al., 1966) were employed in an attempt to determine the site of the amino acid substitution. After spraying the paper with diluted ninhydrin the variant peptide was eluted with $0.1 \mathrm{~N} \mathrm{HCl}$ and the standard amino acid composition determinations made.

Difference spectra, between free and enzyme bound Neoprontosil, were determined using a Beckman Acta II recording spectrophotometer. Heat denaturation results were determined by incubation of the enzyme in a thermostated glass vessel with the monitoring of enzyme concentration by a sulfonamide binding assay. Both of these methods have been fully described (Osborne and Tashian, 1974).

\section{Results and Discussion}

Ueda (1974) has previously reported detecting two examples of the CA Th Hiroshima variant in a group of 1200 Japanese. A recent extension of these initial studies has resulted in ascertaining two additional examples to a total surveyed population of 3969 (Ueda et al., in manuscript).

All 4 proposita were Hiroshima adults born prior to the atomic bombing. A review of the Japanese Koseki records of these 4 individuals, extending back three generations, revealed no common ancestor. The calculated gene frequency, 0.0005 , is at the low end of the gene frequencies for human CA I variants reported by Tashian and Carter (1976) for several human populations. Lie-Injo and co-workers have reported a much higher gene frequency, 0.003 , for the CA Ic variant in mongoloid populations of the southern Pacific region. To date, there has been only one other reported survey of the Japanese population for variation. of red cell CA I (Suijama and Umeda, 1970). These investigators surveyed some 2000 individuals in Nagasaki, Japan and observed no electrophoretic variants of CA I. This is in agreement with the findings of Ueda et al. (in manuscript) that no electrophoretic variants were detected during a recent screening of individuals from that area. 


\section{Thermal Stability}

The results of the thermal denaturation studies are shown in Figure 1 and indicate that $\mathrm{CA}$ Ih is less stable than normal CA I, with first order rate constants for denaturation of $3.7 \times 10^{-4} \mathrm{~s}^{-1}$ and $2.5 \times 10^{-4} \mathrm{~s}^{-1}$ respectively. Two other CA I variants, CA If London and CA Id Michigan, have previously been tested (Osborne and Tashian, 1974) and have first order rate constants for denaturation at $57^{\circ} \mathrm{C}$ of $3.5 \times 10^{-4} \mathrm{~s}^{-1}$ and $1.9 \times 10^{-4} \mathrm{~s}^{-1}$ respectively. Thus, the Hiroshima variant follows the more general pattern of being less stable than the normal isoenzyme, and in this case having a heat stability similar to that of CA If London.

The instability of CA Ih was observed, during the course of this work, in yet another way. Following starch gel electrophoresis of chloroform-ethanol extracted material, visual comparison of the intensity of the normal CA I and CA Ih bands stained with amido black suggested about equal amounts of normal and variant material. However, during the isolation procedure it appeared the $\mathrm{CA}$ Ih was unstable as evidenced by approximately a 5 -fold loss of material relative to normal CA I. This apparent instability occurred despite routine precautions taken to prevent protein denaturation.

\section{Azosulfonamide Difference Spectra}

This technique involves measuring difference spectra using Neoprontosil, an azosulfonamide, which is a specific non-competitive inhibitor of carbonic anhydrase (Coleman, 1968). The absorption profile, primarily located in the visible spectrum, is altered upon binding to carbonic anhydrase and thus can be used to quantitatively estimate the enzyme concentration (Osborne and Tashian, 1974); also, changes in the active site cavity may be reflected in an altered absorption profile.

In Figure 2 are shown the difference spectra of CA I and CA Ih. It can be seen that $\mathrm{CA}$ Ih has a very different spectra relative to $\mathrm{CA} I$, the difference molar extinction coefficient at $490 \mathrm{~nm}$ being $5 \times 10^{3} 1 \mathrm{~mole}^{-1} \mathrm{~cm}^{-1}$ for $\mathrm{CA}$ Ih and $7.7 \times 10^{3} \mathrm{I}$ mole ${ }^{-1} \mathrm{~cm}^{-1}$ for normal CA I. The previously tested CA If and CA Id variants had

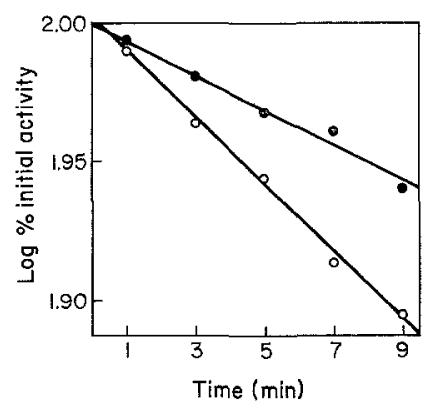

Fig. 1. Heat degradation of normal CA I (•) and CA Ih Hiroshima (o) at $57^{\circ} \mathrm{C}$ in $10 \mathrm{mM}$ HEPES buffer at $\mathrm{pH} 8.0$ 


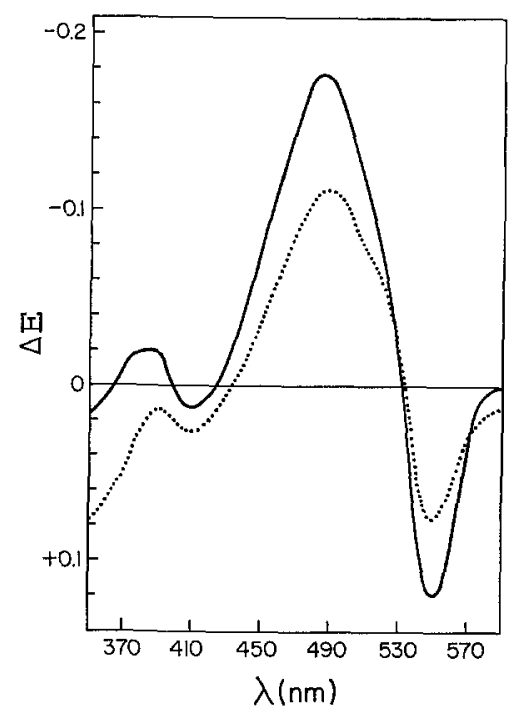

Fig. 2. Difference spectra at pH 7.5 of the Neoprontosil complexes of normal CA I $(\longrightarrow)$ and $\mathrm{CA}$ Ih Hiroshima (- - ). These spectra were done at $25^{\circ} \mathrm{C}$ using $0.1 \mathrm{M}$ HEPES, pH 7.5. The following enzyme concentrations were used: CA I $22 \mu \mathrm{M}$ and CA Ih $24 \mu \mathrm{M}$. In both cases the spectral difference is between free and protein bound inhibitor

molar extinction values the same as the normal. No comparable data exist for the CA Ic variant.

\section{Tryptic Peptide Patterns}

The standard tryptic fingerprint techniques used in this study provided no evidence of the Arg-Arg dipeptide characteristic of the CA Ic Guam variant. Furthermore, the corresponding Gly-Arg dipeptide seen in tryptic digests of normal CA I, was present in the fingerprints of CA Ih Hiroshima. These observations in themselves provide evidence that the Japanese and Micronesian (CA Ic Guam) variants are the result of different amino acid substitutions.

However, comparison of paper fingerprints of highly purified normal and variant material revealed the presence of a new strongly ninhydrin positive spot in the fingerprint of CA Ih Hiroshima (Fig. 3). We were unable to identify the absence of a corresponding peptide in a normal fingerprint. The new peptide was isolated from the fingerprint and the amino acid composition determined. The composition results suggested this new peptide was comprised of one residue of serine and one residue of lysine; based on the mechanism of action of trypsin this would mean the sequence is Ser-Lys. After reviewing the published sequence of human CA I (Andersson et al., 1972), and by assuming the substitution is the result of a single nucleotide replacement, there is clearly only one position in the sequence which could give rise to a Ser-Lys depiptide. This unique position is residue 16 which is a tryptophan in the normal enzyme, and we propose, on the basis of our results, that this has been replaced by an arginine in the CA Ih molecule. At this time, 


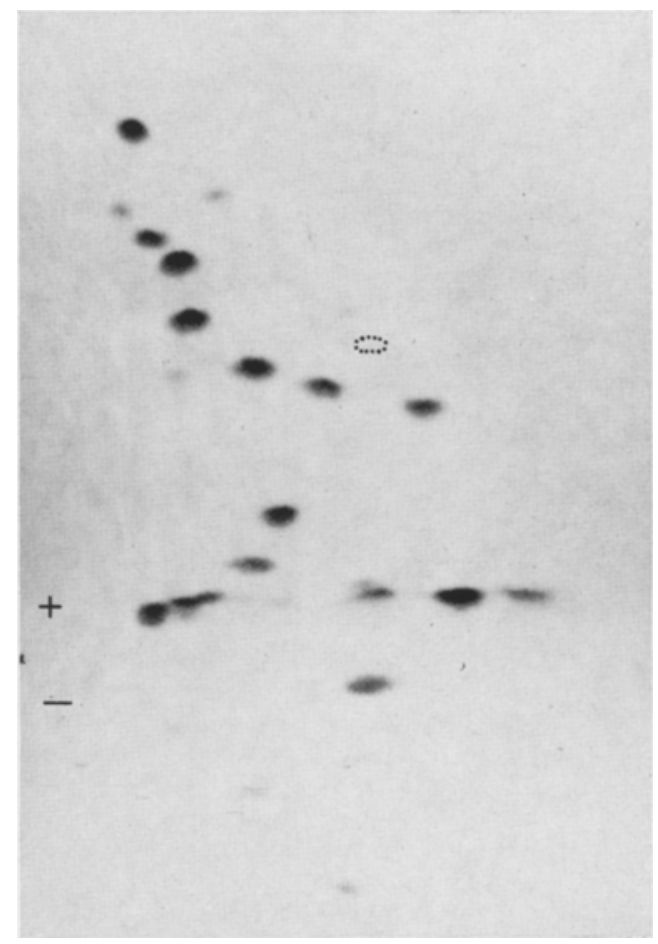

Fig. 3. Tryptic peptide pattern of normal human red cell carbonic anbydrase I showing the location of the single variant peptide found in the $\mathrm{CA}$ Ih material

the other examples of the CA Ic variant have not been characterized to the point where the amino acid substitution has been determined. Thus, it is not known if they represent additional examples of the Guam variant or additional examples of the Japanese variant. Also possible is that they are the result of a unique amino acid substitution corresponding to neither of the above two.

The above proposal is consistent with the observed migration behavior on starch gel electrophoresis, and furthermore correlated with observations made during the difference spectra experiments. It should be pointed out that changes in the Neoprontosil difference spectra of the variant could be due to underestimation of protein concentration, changes in the active site area, or a combination of both. The proposed substitution would have a combined effect because tryptophan contributes greatly to the $280 \mathrm{~nm}$ extinction of proteins (Edelhoch, 1967), and therefore the substitution at position $16^{\mathrm{Trp}} \rightarrow$ Arg would result in the underestimation of protein concentration. Further, Trp 16 is part of the aromatic cluster $I$, seen in the X-ray structure work, and is known to be close to the active site region (Notstrand et al., 1975). Thus, altered binding of the ligand, due to the substitution, could easily contribute to the observed differences.

This work was supported in part by ERDA Contract E(11-1)-1552 (to J. V. Neel) and U.S. Public Health Service Grant GM-15419. 


\title{
References
}

Andersson, B., Nyman, P. O., Strid, L.: Amino acid sequence of human erythrocyte carbonic anhydrase B. Biochem. biophys. Res. Commun. 48, 670-677 (1972)

Coleman, J. E. : Carbonic anhydrase-azosulfonamide complexes. J. biol. Chem. 243, 4574-4587 (1968)

Edelhoch, M.: Spectroscopic determination of tryptophan and tyrosine in proteins. Biochemistry 6, 1948-1954 (1967)

Lie-Injo, L. E.: Red cell carbonic anhydrase Ic in Filipinos. Amer. J. hum. Genet. 19, 130-132 (1967)

Lie-Injo, L. E., McKay, D. A., Govindasamy, S.: Genetic red cell abnormalities in Trenqqanu and Perlis (West Malaysia). Southeast Asian J. Trop. Med. Pub. Health 2, 133-135 (1971)

Lie-Injo, L. E., Poey-Oey, M. G.: Phosphoglucomutase, carbonic anhydrase and catalase in Indonesians. Hum. Hered. 20, 215-219 (1970)

Notstrand, B., Vaara, I., Kannan, K. K.: Structural relationship of human erythrocyte carbonic anhydrase isozymes B and C. In: Isozymes (ed. L. Markert), Vol. 1, pp. 575-599. New York: Academic Press 1975

Osborne, W. R., Tashian, R. E.: Thermal inactivation studies of normal and variant human erythrocyte carbonic anhydrases by using a sulphonamide-binding assay. Biochem. J. 141, 219-225 (1974)

Osborne, W. R., Tashian, R. E.: An improved method for the purification of carbonic anhydrase isozymes by affinity chromatography. Anal. Biochem. 64, 297-303 (1975)

Suyama, H., Umeda, K.: A study on carbonic anhydrase variants. Jap. J. Legal Med. 24, $391(1970)$

Tashian, R. E., Carter, N. D.: Biochemical genetics of carbonic anhydrase. In: Advances in human genetics (eds. K. Hirschhorn, H. Harris), Vol. 7, pp. 1-55. New York: Plenum Press 1976

Tashian, R. E., Plato, C. C., Shows, T. B.: Inherited variant of erythrocyte carbonic anhydrase in Micronesians from Guam and Saipan. Science 140, 53-54 (1963)

Tashian, R. E., Riggs, S. K., Yu, Y.S.: Characterization of a mutant human erythrocyte carbonic anhydrase: Carbonic anhydrase Ie Guam. Arch. Biochem. Biophys. 117, 320-327 (1966)

Ueda, N.: New Japanese variant of human erythrocyte carbonic anhydrase. Jap. J. hum. Genet. 19, 161-167 (1974)

Ueda, N., Satoh, C., Tanis, R. J., Ferrell, R. E., Kishimoto, S., Neel, J. V., Hamilton, H. B., Baba, K.: The frequency in Japanese of genetic variants of 22 proteins. II. Carbonic anhydrase I and II, lactate dehydrogenase, malate dehydrogenase, nucleoside phosphorylase, triosephosphate isomerase, hemoglobin $A$, and hemoglobin $A_{2}$. In manuscript

\author{
Dr. Robert J. Tanis \\ Department of Human Genetics \\ University of Michigan School of Medicine \\ Ann Arbor, Michigan 48109, USA
}

